\title{
TRANSITIVITAS FILM "PADA ZAMAN DAHULU" DI MNCTV DAN RELEVANSINYA DENGAN PEMBELAJARAN TEKS FABEL DI SEKOLAH
}

\author{
Yuni Hajar \\ Universitas Negeri Medan
}

Abstrak

Korespondensi: yunihajarazkia@gmail.com

Penelitian ini mengkaji tentang Film Pada Zaman Dabulu di MNCTV dengan menggunakan teori Linguistik Fungsional Sistemik (LFS) yang direlevansikan dengan pembelajaran teks fabel di sekolah. Penelitian ini difokuskan pada fungsi pertukaran yang direalisasikan dalam sistem nilai transitivitas yang mendominasi film Pada Zaman Dabulu di MNCTV. Metode yang digunakan pada penelitian ini yaitu deskriptif kualitatif dengan teknik Content Analysis. Hasil penelitian ini ditemukan transitivitas yang paling banyak muncul ialah partisipan sebanyak 39 butir atau 34,8\%, kedua ilah sirkumstan sebanyak 38 butir atau 33,9\%. Sedangkan tipe proses yang dominan yakni proses material sebanyak 21 butir atau 18,7\%, proses mental sebanyak 4 butir atau 3,6 \%, relasional sebanyak 4 butir atau 3,6\%, proses verbal, proses wujud dan proses behavioral sebanyak 2 butir atau 1,8\%. Semua pola ini dapat digunakan sebagai acuan dalam menulis teks fabel di sekolah, khususnya kelas VII SMP.

Kata Kunci: Linguistik Fungsional Sistemik (LFS), Transitivitas Film, Teks Fabel

\section{Abstract}

This study examines the Films of the Early Days at MNCTV using the Systemic Functional Linguistic Theory (LFS) which is relevant to learning fable texts in schools. This research is focused on the exchange function which is realized in the transitivity value system that dominated the film of the Past in MNCTV. The method used in this research is descriptive qualitative with Content Analysis technique. The results of this study found that the most emergent transitivity were participants as many as 39 items or $34.8 \%$, the two circumstan gods were 38 items or $33.9 \%$. While the dominant type of process is 21 items or $18.7 \%, 4$ items or $3.6 \%$ mental process, 4 items or $3.6 \%$ relational, verbal processes, forms and behavioral processes 2 items or $1.8 \%$. All of these patterns can be used as a reference in writing fable texts in schools, especially grade VII junior high school.

Keywords: Systemic Functional Linguistics (LFS), Film Transitivity, Fable Text

\section{PENDAHULUAN}

Bahasa terbentuk berdasarkan tujuan-tujuannya yang mengacu pada aturan dalam fungsi dasar bahasa. Fungsi dasar dalam sebuah bahasa disebut juga dengan metafungsi bahasa. Metafungsi bahasa berkaitan dengan pengalaman penulis, baik yang bersifat lahir atau batin. Dari pengalaman-pengalaman tersebut akan muncul ide-ide yang merepresentasikan pengalaman pengarang. Setelah itu, ide-ide tersebut akan 


\section{Yuni Hajar}

direalisasikan dalam bentuk konstituen kalimat yang saling berhubungan antara satu dengan yang lainnya.

Ketransitifan atau transitivitas merupakan wujud realisasi gramatika dari fungsi ideasional. Sistem ketransitifan sebuah bahasa menggambarkan fakta bahwa pengalaman ditafsirkan sebagai perangkat ranah terbatas tentang makna yang berbeda sesuai dengan tipe proses dan sifat partisipan yang terlibat di dalamnya, serta dihubungkan dengan tipe sirkumtan yang berbeda (Rumnasari, 2009:21)

Trasitivitas dapat diindetifikasi berdasarkan proses, partisipan, dan sirkumtan. Dalam transitivitas, inti dari pengalaman adalah proses, maka dalam tataran klausa, proses menentukan jumlah dan kategori partisipan, serta menentukan sirkumtan secara tidak langsung dalam tataran klausa tersebut (Adisaputra, 2008:13).

Proses mampu menentukan jumlah dan kategori partisipan, serta menentukan sirkumtan yang secara tidak langsung berkaitan dengan probabilitas (Adisaputra, 2008: 13). Halliday (2004:171) berpendapat bahwa proses material, mental, dan relasional merupakan proses utama dalam sisitem ketransitifan, sedangkan proses verbal, perilaku (behavior), dan eksistensial merupakan tipe proses yang terdapat di antara ketiga proses utama tersebut.

Film 'Pada Zaman Dahulu' adalah sebuah serial animasi berupa kisah dongeng yang diproduksi oleh Les' Copaque. Film ini memiliki beberapa judul, alur dan juga beberapa tokoh yang berbeda. Contohnya pada episode 'Kancil dan Harimau", film yang berdurasi 17 menit dan dirilis pada tahun 2015, yang disutradarai oleh $\mathrm{Hj}$. Burhanuddin bin MD Radzi adalah film terbaik di Malaysia pada tahun 2015.

Film animasi "Pada Zaman Dahulu" merupakan media film animasi 3D yang berasal dari negara Malaysia yang kemudian ditayangkan di salah satu stasiun televisi yang ada di Indonesia yaitu MNCTV. Meskipun berasal dari negara Malaysia tetapi ini memberikan dampak positif bagi anak-anak karena minimnya yang diperuntukkan untuk anak-anak. Film animasi "Pada Zaman Dahulu" dijadikan media tanyangan untuk pembelajaran teks menulis fabel, karena ceritannya mengandung pesan moral dan animasi 3D sangat menarik dengan gambar hewan-hewan yang sifatnya menyerupai manusia.

Pembelajaran Kurikulum 2013 pada pembelajaran bahasa Indonesia khususnya tingkat SMP menekankan pada pembelajaran berbasis teks. Teks dapat berwujud teks tertulis maupun teks lisan.Teks merupakan ungkapan pikiran manusia yang lengkap yang di dalamnya memiliki situasi dan konteks. Satu diantara teks pembelajaran bahasa Indonesia adalah cerita fabel. Cerita fabel merupakan cerita fiksi berupa dongeng yang menggambarkan budi pekerti manusia yang diibaratkan pada binatang (Kemdikbud, 2016:201).

Film "Pada Zaman Dahulu" merupakan cerita fabel karena berisi pesan moral manusia yang diibaratkan seperti binatang, dan sangat menarik jika film ini dianalisis berdasarkan transitivitas menggunakan Tata Bahasa Fungsional Halliday. Sehingga dapat memberikan kebermanfaatan pada pembelajaran teks fabel oleh siswa SMP.

Banyak penelitian yang menggunakan Tata Bahasa Fungsional sebagai landasan teori atau alas berpijak dalam penelitian bahasa. Seperti penelitian yang telah dilakukan Sawerigading (2013) berjudul "Transitivitas pada Slogan Iklan Berbahasa Inggris: Pendekatan Tata Bahasa Fungsional (Transitivity in English Slogans: A Functional Grammar Analysis)". Sawerigading menganalisis transitivitas pada slogan iklan mobil. Hasil penelitiannya menunjukkan bahwa transitivitas yang ditemukan dalam slogan iklan mobil berbahasa 
Inggris yaitu: (1) jenis proses dalam bentuk materi, mental, serta bentuk relasional dan (2) slogan-slogan dalam bentuk deklaratif mengandung peserta (subjek).

Sama hal nya dengan penelitian yang dilakukan Tias Oktaviani,dkk (2017) “Transitivitas Teks Anekdot Komunikasi Jenaka Karya Deddy Mulyana”. Tias Oktaviani,dke mengkaji transitivitas yang merupakan realisasi dari fungsi ideasional yang terdapat dalam kumpulan teks anekdot Komunikasi Jenaka sebanyak lima belas teks terpilih. Hasil dari penelitian ini adalah, proses material mendominasi cerita yang hakikatnya sesuai dengan sifat realis yang dimiliki teks anekdot. Kemudian, sirkumtan lokasi yang menyatakan tempat dan waktu menjadi pelengkap paling banyak digunakan pengarang. Selain itu, dalam penelitian ini ditemukan 61 pola kalimat dalam transitivitas teks anekdot tersebut: 18 pola pada proses material, 11 pola pada proses mental, 9 pola pada proses verbal, 8 pola pada proses perilaku, 9 pola pada proses relasional, dan 6 pola pada proses eksistensial. Polapola ini dapat digunakan sebagai acuan dalam membuat strauktur teks anekdot.

Penelitian yang sama juga dilakukan Zul Haeri (2016) berjudul "Kajian Linguistik Fungsional Sistemik pada Terjemahan Al-Quran Surah Al-Insan Dan Relevansinya Terhadap Pembelajaran Wacana di Perguruan Tinggi". Zul Haeri menganalisis 2 hal dari LFS yakni transitivitas dan modalitas pada terjemahan Al-Quran Al-Insan, dan relevansi dengan konteks pembelajaran di pendidikan tinggi. Temuan menunjukkan bahwa sistem transitivitas dan modalitas teks sebagai bahan proses Al-Insan 27 (46,55\%), proses mental sebanyak $9(15: 52 \%)$, proses identifikasi relasional sebanyak 10 (17:24\%), perilaku proses $2(03: 45 \%)$, proses oral sebanyak $1(1,72 \%)$, dan proses sebanyak satu $(1,72 \%)$. Temuan berupa modalitas berbentuk modalitas (probabilitas dan frekuensi) $37(71,15 \%)$ dan modulasi (kebutuhan dan keinginan) 9 (17:37\%).

Setyo Prasiyanto Cahyono (2018) juga mengimplementasikan SFL dalam pengajaran menulis pada penelitiannya yang berjudul "Teaching L2 writing through the use of Systemic Functional Linguistics (SFL)”. Penelitian ini bertujuan untuk menggambarkan implementasi linguistik fungsional sistemik (SFL) dari tata bahasa teks pesan (atau makna tekstual) untuk meningkatkan respons kritis siswa terhadap teks yang mereka buat. Penelitian ini bermaksud untuk mendekati pengajaran menulis dengan mengadopsi ide Halliday tentang makna tekstual dan Systemic Functional Linguistics (SFL). Analisis teks siswa menunjukkan bahwa sebagian besar siswa dapat mengedit sendiri tulisan mereka dan mengedit tulisan rekan mereka menggunakan perkembangan tematik dan perangkat kohesif. Siswa mengadopsi keterampilan menggunakan kedua strategi dalam menciptakan keterpaduan dalam tulisan mereka. Selain itu, siswa juga menghasilkan respons kritis terhadap topik yang diberikan melalui tema dan tematik yang ditampilkan dalam analisis teks.

Analisis Linguistik Fungsional Sistemik (SFL) juga diterapkan pada pembelajaran teks, seperti teks eksposisi. Seperti pada penelitian yang dilakukan R. Winda Herdisa Dewi (2016) yang berjudul "A Systemic Functional Linguistic (SFL) Analysis of exposition text as teaching materials written by Pre-Service Teachers". Penelitian ini bertujuan untuk mengamati kompetensi Pengetahuan Subjek Materi Guru dengan menganalisis koherensi teks eksposisi analitis yang ditulis oleh tiga guru bahasa Inggris di sekolah menengah atas dalam hal struktur skematik dan sistem tema mereka. Studi ini menemukan bahwa guru preservice mampu membuat teks koheren dilihat dari Tema dan Kemajuan Tematik yang diterapkan dalam teks. Dalam hal tema, semua guru pre-service cenderung menggunakan 


\section{Yuni Hajar}

tema yang tidak ditandai dan bukan tema lain. Mereka berusaha terus mengidentifikasi topik yang sedang dijabarkan dengan menggunakan tema yang tidak ditandai.

Selain diterapkan pada teks, Linguistik Fungsional Sistemik (SFL) juga diterapkan pada karya satra yang dilakukan oleh Suddin M. Saleh Djumadil (2016) dengan judul "Puisi 'Kemuning'karya Sanusi Pane Analisis Skala, Kategori, Linguistik Sistemik Fungsional Halliday, dan Semiotika Peirce". Penelitian ini bertujuan untuk menganalisis sebuah puisi berjudul 'Kemuning' karya Sanusi Pane dengan mengunakan Skala dan kategori (unit dan struktur) linguistik sistemik fungsional yang dikembangkan oleh Halliday dan semiotik Pierce. Hasil penelitian ini yakni pada bagian analisis struktur ditemukan fungsi gramatika antara lain ialah subjek, objek, predikat, keterangan atau ajung. Pada analisis ideasional atau fungsional semantik secara sintagmatik ditemukan actor, partisipan, proses aktif, proses pasif, temporal waktu, conjungtif, frasa preposisi, ajung atau keterangan. Kemudian analisis puisi Sanusi Pane dengan pendekatan semiotika Peirce ditemukan tanda yang berupa simbol dan sebagian besar ditemukan tanda berupa indeks.

Berdasarkan penelitian-penelitian yang telah dilakukan di atas mengenai SFL ini, belum ada dilakukan penelitian mengenai transitivitas pada sebuah film. Sehingga dapat dikatakan penelitian transitivitas film "Pada Zaman Dahulu" terbilang baru. Hasil analisis ini dapat direlevansikan pada pembelajaran teks fabel di SMP. Maka dengan ini penulis akan melakukan penelitian dengan judul "Transitivitas Film "Pada Zaman Dabulu" di MNCTV dan Relevansinya dengan Pembelajaran Teks Fabel di Sekolah”.

\section{METODE}

Dalam penelitian ini peneliti menggunakan meode deskriptif kualitatif dengan menggunakan teknik analisis isi (content analysis). Holsti dalam Lexy J. Moeloeng (2013) memberikan definisi bahwa analisis isi adalah teknik yang digunakan untuk menarik kesimpulan melalui usaha menemukan karakteristik pesan. Peneliti menggunakan teknik analisis isi (content analysis) adalah merupakan analisis ilmiah tentang isi pesan suatu komunikasi yang ada. Dalam content analysis ini menampilkan tiga syarat yaitu objektif, pendekatan sistematis dan generalisasi. Sedangkan menurut Wazer dan Wiener analisis isi adalah suatu prosedur sistematik yang disusun untuk menguji isi informasi yang terekam (Difika, 2016: 9).

Data primer merupakan data penelitian yang diperoleh secara langsung dari sumber asli tidak melalui perantara (Sangadji \& MM, 2010: 171). Sumber data primer yang dimaksud di sini adalah sumber data yang digali langsung dari film yang dijadikan obyek penelitian. Dalam pembahasan ini, sumber primernya adalah film Pada Zaman Dahulu Episode Kancil dan Harimau di MNCTV yang dikemas dalam bentuk video dan tayangan di chanel youtube les' copaque production.

Sumber data dalam penelitian ini adalah film, yang berarti data yang terdokumentasi, maka teknik yang perlu dijalankan adalah dokumentasi, yaitu mencari data mengenai hal-hal atau variabel yang berupa catatan, transkip, buku, surat kabar, majalah, prasasti, agenda dan lain sebagainya, Bachtiar 1997: 77(Fuad, 2017: 17). Teknik ini dilakukan untuk mendefinisikan data dalam film "Pada Zaman Dahulu" dan bahanbahan lain yang berkaitan dengan judul penelitian ini.

Prosedur untuk mengumpulkan data dalam penelitian ini ada tiga langkah. Pertama, peneliti menentukan objek film "Pada Zaman Dahulu", yakni yang berjudul "Kancil dan Harimau". Kedua, peneliti melakukan pencatatan/ transkrip melalui video. 
Ketiga, menganalisis transivitas yang terdapat pada data (proses material, mental, relational)

Interpretasi data dalam penelitian ini dilakukan dengan langkah sebagai berikut. Pertama, peneliti melakukan pembacaan teks film "Pada Zaman Dahulu" yang berjudul "Kancil dan Harimau". Kedua, peneliti menganalisis teks berdasarkan transitivitas linguistic fungsional Halliday. Ketiga, peneliti melakukan inferensi dengan cara mengonfirmasikan temuan dengan literatur yang berkait dengan linguistic fungsional Halliday..

\section{HASIL DAN PEMBAHASAN}

Analisis Transitivitas film "Pada Zaman Dahulu" dengan judul "Kancil dan Harimau"

\section{* Analisis 1}

"Kancil sedang berjalan-jalan di butan"

Kancil Sedang Berjalan-jalan di hutam

Participan Proses material sirkumstan

\section{* Analisis 2}

"Ketika sedang asik-asik berjalan makan rumput"

Ketika sedang asik berjalan-jalan makan rumput

$\begin{array}{lll}\text { Sirkumstan } & \text { Proses material Proses material }\end{array}$

* Analisis 3

"Tiba-tiba Kancil dikagetkean suara auman di depannya"

$\begin{array}{lllll}\text { tiba-tiba } & \text { Kancil } & \text { dikagetkan } & \text { suara auman } & \text { di depannya } \\ \text { sirkumustan } & \text { participan } & \text { Proses mental } & \text { participan } & \text { sirkumstan }\end{array}$

sirkumustan participan Proses mental participan sirkumstan

\section{Analisis 4}

"Hei Kancil siap-siap ku makan nib"
Hei Kancil
siap-siap
ku makan nih
partisipan
sirkumstan
Proses material

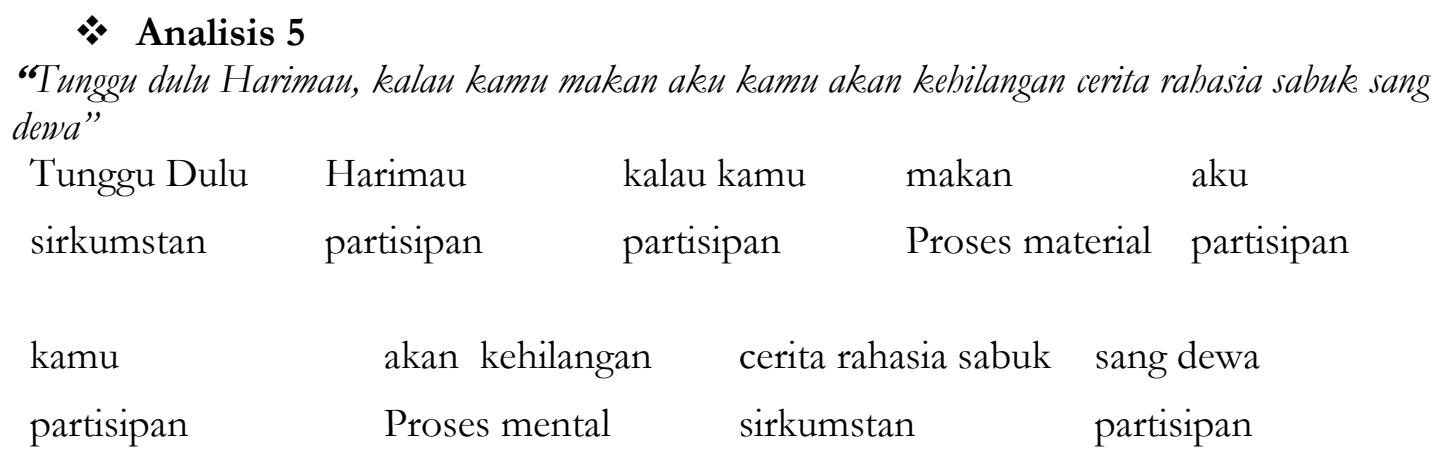

Analisis 6 
"Merekapun segera berjalan menuju pinngir sungai di selatan butan"

Merekapun segera berjalan menuju pinggir sungai di selatan hutan

participan sirkumstan Proses material sirkumstan

\section{Analisis 7}

"Dan ketika tububnya memasuki kedalam lingkaran tersebut, tiba-tiba benda tersebut bergerak melilit tubub harimau"

$\begin{array}{llll}\text { Dan ketika } & \text { tubuhnya } & \text { memasuki } & \begin{array}{l}\text { kedalam lingkaran } \\ \text { tersebut } \\ \text { sirkumstan }\end{array} \\ \text { tiba-tiba } & \text { partisipan } & \text { Proses material } & \text { siran } \\ \text { sirkumstan } & \text { benda tersebut } & \text { Bergerak melilit } & \text { tubuh Harimau } \\ & \text { partisipan } & \text { Proses material } & \text { partisipan }\end{array}$

\section{Analisis 8}

"dan Alangkeab kagetnya harimau ketika dihadapannya muncul kepala ular piton di depannya"

Dan alangkah Harimau ketika Muncul kepala di

kagetnya dihadapannya ular piton depannya

Proses mental partisipan sirkumstan Proses wujud sirkumstan

Tipe Transitivitas yang Mendominasi film "Pada Zaman Dahulu" dengan judul "Kancil dan Harimau"

Berdasarkan analisis transitivitas di atas, ditemukan 112 klausa. Penghitungan dimunculkan dalam bentuk tabel sebagai berikut.

\begin{tabular}{llll}
\hline No & Jenis Transitivitas & Jumlah & Persentase $\%$ \\
\hline 1 & Proses Material & 21 & $18,7 \%$ \\
2 & Proses Mental & 4 & $3,6 \%$ \\
3 & Proses Relasional & 4 & $3,6 \%$ \\
4 & Proses Verbal & 2 & $1,8 \%$ \\
5 & Proses Wujud & 2 & $1,8 \%$ \\
6 & Proses Behavioral & 2 & $1,8 \%$ \\
7 & Participan & 39 & $34,8 \%$ \\
8 & Sirkumstan & 38 & $33,9 \%$ \\
\hline
\end{tabular}

Berdasarkan persentase tabel di atas, bahwa transitivitas yang paling banyak muncul ialah partisipan sebanyak 39 butir atau 34,8\%, kedua ilah sirkumstan sebanyak 38 butir atau $33,9 \%$. Sedangkan tipe proses yang dominan yakni proses material sebanyak 21 butir atau $18,7 \%$, proses mental sebanyak 4 butir atau 3,6\%, relasional sebanyak 4 butir atau 3,6 $\%$, proses verbal, proses wujud dan proses behavioral sebanyak 2 butir atau 1,8 \%.

Jadi jika dilihat dalam tabel di atas maka proses material yang mendominasi yang merupakan aktivitas fisik yang nyata dilakukan pelakunya, disusul oleh proses mental yang 
menunjukkan aktivitas yag menyangkut indera, kognisi, emosi, dan persepsi yang terjadi di dalam batin, kemudian relasional yang menghubungkan satu entitas dengan maujud atau lingkungan lain di dalam intensif, setelah itu proses verbal, wujud dan behavioral yang memiliki jumlah yang sama.

Tingginya jumlah proses material yang terdapat dalam teks tersebut menunjukan bahwa, fil ini lebih memperlihatkan adanya aktivitas fisik yang banyak terdapat dalam film "Pada Zaman Dahulu" yang berjudul "Kancil dan Harimau". Aktivitas fisik tersebut dapat ditunjukan melalui kegiatan-kegiatan yang dilakukan oleh para tokoh dan atau dengan melibatkan tokoh dan entitas lainnya.

Kemudian, dalam transitivitas suatu proses yang terdapat dalam tataran kalusa merupakan unsur utama dalam sebuah teks. Hal ini dikarenakan dalam suatu proses tersebut akan mempengaruhi kehadiran dari peran partisipan itu sendiri, baik secara kualitas ataupun kuantitasnya. Selain itu, ada unsur lain yang juga dipengaruhi kehadiran dari proses dan partisipan, yaitu sirkumtan. Sirkumtan memiliki sifat yang tidak wajib hadir dalam tataran klausa. Namun, kehadiran dari unsur sirkumtan ini tidak dapat dikesampingkan begitu saja, karena sirkumtan dapat pula memberikan keteranganketerangan pendukung dalam sebuah klausa, sehingga pemaknaan dalam film tersebut menjadi utuh.

Hasil penelitian ini, sesuai dengan penelitian Tias Oktaviani dkk (2017) yang menganilisis transitivitas teks anekdot, yakni jumlah proses mental menjadi paling dominan ketimbang proses yang lain.

\section{Relevansi Hasil Kajian Transitivitas Film "Pada Zaman Dahulu” di MNCTV Terhadap Pembelajaran Teks Fabel di Sekolah}

Relevansi hasil kajian penelitian terhadap pembelajaran teks fabel pada penelitian ini difokuskan pada sistem transitivitas. Film "Pada Zaman Dahulu" dapat dijadikan sarana media belajar bagi siswa kelas VII SMP untuk meningkatkan kemampuan menulis teks fabel. Karena pada film ini berisi tentang menceritakan kehidupan hewan yang berperilaku menyerupai manusia, memberikan ajaran moral dengan menunjukkan sifatsifat jelek manusia melalui simbol binatang-binatang. Melalui tokoh binatang, pengarang ingin mempengaruhi pembaca agar mencontoh yang baik dan tidak mencontoh yang tidak baik. Sehingga film ini dapat membangun siswa untuk menambah wawasan dalam menulis teks fabel.

Melalui analisis transitivitas, dapat diketahui bahwa dalam menulis teks fabel nantinya, siswa harus memperhatikan proses, partisipan dan sirkumstan untuk membangun cerita yang bermakna dan hidup. Proses yang dominan dalam menulis teks fabel tentulah proses material, yang merupakan aktivitas fisik yang nyata dilakukan pelakunya. Dan untuk melakukan aktivitas fisik tersebut diperlukan partisipan atau tokoh yang berperan dalam cerita teks fabel. Agar cerita dapat hidup dan dimaknai kondisi suasa, latar, maka sirkumstan juga dimunculkan pada teks fabel ini. Sehingga pembaca dapat memahami latar tempat, waktu dan suasan dari setiap kejadian yang dialami partisipan.

\section{PENUTUP}

Secara keseluruhan bahwa transitivitas yang paling banyak muncul ialah partisipan sebanyak 39 butir atau 34,8\%, kedua ilah sirkumstan sebanyak 38 butir atau 33,9\%. Sedangkan tipe proses yang dominan yakni proses material sebanyak 21 butir atau 18,7\%, 
proses mental sebanyak 4 butir atau 3,6 \%, relasional sebanyak 4 butir atau 3,6 \%, proses verbal, proses wujud dan proses behavioral sebanyak 2 butir atau 1,8\%.

Semua pola ini dapat digunakan sebagai acuan dalam menulis teks fabel di sekolah, khususnya kelas VII SMP. Analisis ini memberikan relevansi terhadap kegiatan belajar mengajar di sekolah, yakni untuk meningkatkan kemampuan siswa dalam menulis teks fabel.

\section{DAFTAR RUJUKAN}

Fuad, T. (2017). Pesan Dakwah Dalam Film Animasi “Adit dan Sopo Jarwo." Semarang: UIN Walisongo Semarang.

Halliday, \& Hassan, R. (1992). Bahasa, Konteks, dan Teks: Aspek-aspek Bahasa dalam Pandangan Semiotik Sosial (B. Tou, ed.). Yogyakarta: Gadjah Mada University Press.

Kemdikbud. (2016). Buku Guru Bahasa Indonesia Kelas VII SMP/MTs. Jakarta: Kementrian Pendidikan dan Kebudayaan Republik Indonesia.

Moleong, L. j. (2013). Metode Penelitian Kualitatif. Bandung: PT. Remaja Rosdakarya.

Oktaviani, T. (2017). Transitivitas Teks Anekdot Komunikasi Jenaka Karya Deddy Mulyana. Jurnal Arkhais, 8(1).

Sangadji, E. mamang, \& Sopiah. (2010). Metodologi Penelitian-Pendekatan Praktis Dalam Penelitian. Yogyakarta: C.V Andi Offset. 